\title{
UNA APROXIMACIÓN TEÓRICO JURÍDICA AL CONVENIO COLECTIVO
}

Federico Fernández-Crehuet

Universidad de Almería

\section{Introducción}

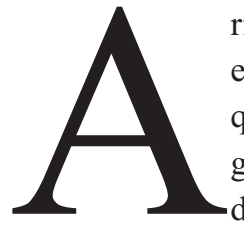

ristóteles ya sostuvo que las actividades cuyo fin reside en ellas mismas son superiores ${ }^{1}$. La reflexión filosófica, pues, que no posee ninguna utilidad, sería una de ellas. Sin embargo, parece que, aunque la máxima aristotélica no está exenta de razón, una cierta conexión con los problemas reales no será un defecto de las reflexiones filosóficas sino una virtud. Indudable, también, que cuando las digresiones filosóficas hollan el terreno jurídico deben guardar una íntima relación con los problemas jurídicos reales. En estas líneas pretendemos no perder de vista, en la medida de lo posible, esta máxima, orientando la filosofía del derecho hacia algunas zonas de penumbra del derecho positivo, en concreto, hacia la teoría de fuentes en el ámbito laboral. En este sentido, creo que la filosofía del derecho debe ser más permeable a los problemas surgidos en los diversos sectores del ordenamiento jurídico. No se trata, desde luego, de elevarla a la categoría de meta-ciencia jurídica, que domeñe las disciplinas positivas.

Aunque la interdisciplinariedad es en la actualidad defendida desde la filosofía del derecho, las aproximaciones al derecho laboral son escasas ${ }^{2}$. En este trabajo no se pretende solucionar todas las dificultades generadas en torno a la negociación colectiva y su relación con la teoría general de fuentes; más bien, quisiera tan sólo esbozar un esquema, una lista de problemas

\footnotetext{
${ }^{1}$ Aristóteles, Ética a Nicómaco, Madrid, Centro de Estudios Políticos y Constitucionales, 1999, 1094 a.

${ }^{2}$ Ad exemplum cfr. García Amado, A., "El individuo y los grupos en el derecho laboral. Los dilemas del vínculo social" en Cuadernos electrónicos de Filosofía del Derecho núm. 2, 1999. Y el trabajo de AdomeIt, K., Rechtsquellenfragen im Arbeitsrecht, München, Beck, 1969.
} 
que tienen conexiones entre sí y que no pueden ser solventados aisladamente ni desde la perspectiva iuslaboralista ni desde la iusfilosófica.

De modo muy general, se podría afirmar que este mapa de problemas gira en torno a la caracterización de la negociación colectiva y de su resultado institucional, el convenio colectivo, en la teoría general de fuentes. El trabajo se divide en tres partes bien diferenciadas; en la primera de ellas, recojo dos conceptos fundamentales para el desarrollo del trabajo: las reglas que confieren poderes y la teoría de las fuentes-acto, que después utilizaré para explicar el convenio colectivo (Apartado II). En la segunda parte, analizo sucintamente cuáles son los elementos que conforman el convenio colectivo (Apartado III a VIII inclusive) y, por último, como conclusión, se esbozan algunos rasgos de la naturaleza de esta institución jurídica ${ }^{3}$.

\section{Las reglas que confieren poderes}

Hart ha puesto de manifiesto la imposibilidad de explicar los sistemas jurídicos modernos por medio de un único tipo de normas jurídicas. Es un lugar común de la filosofía del derecho contemporánea afirmar que los sistemas jurídicos están compuestos, al menos, por dos clases de normas jurídicas: normas respaldadas por amenazas ${ }^{4}$ y normas que confieren poderes (en adelante, RCP) $)^{5}$. Esta diferencia encuentra su razón de ser -entre otras- en la constitución compleja del sistema social y del jurídico; de tal suerte, que el soberano debe transferir ciertas competencias a otros sujetos para facilitar el mantenimiento del poder y la fluidez en las relaciones jurídicas. Tan sólo una sociedad sencilla, casi proto-jurídica, sería sostenible por medio de reglas respaldadas por amenazas. Este último aserto es predicable especialmente de la negociación colectiva. Las sociedades y sistemas jurídicos en los que se lleva a cabo la negociación colectiva son, usualmente, sociedades complejas e industrializadas, donde un sistema jurídico normativo cons-

\footnotetext{
${ }^{3}$ La idea de institución jurídica no se puede reducir a una norma, ni tampoco a un mero conjunto de normas. La institución sobrepasa estos límites. Desde luego, no pretendemos afrontar el espinoso problema de qué sea una institución jurídica. Santi Romano sostiene, al respecto: "esto significa que el derecho antes que ser norma, antes que implicar una simple relación o una serie de relaciones sociales, es sobre todo organización, estructura, posición de la sociedad misma en la que se desarrolla, y que precisamente el derecho constituye como unidad, como ente con sustantividad propia”. Romano, S., El ordenamiento jurídico, Madrid, Instituto de Estudios políticos, 1963, p. 113. Sobre el concepto de institución véase también p. 122-131. Existe, desde luego, una visión más moderna del institucionalismo. Un intento serio y fundamentado, que afronta esta tarea, puede hallarse en LA TorRe, M., "Instituionalism Old and New" en Ratio Iuris, vol. 6, núm. 2, julio 1993, pp. 196-99, y también en Ansuategu, F. J., El positivismo jurídico neoinstitucionalista, Madrid, Dykinson, 1996, p. 163 y ss.

${ }^{4}$ Hart. H. L. A., El concepto de Derecho, Buenos Aires, Ed. Porrúa, 1995, p. 25 y 45.

${ }^{5}$ Hart. H. L. A., Op. cit., p. 52.
} 
truido únicamente por reglas respaldadas por amenazas sería insostenible. En ellas, más bien, se requiere un sistema jurídico con reglas que permitan que las competencias tradicionales del legislador se distribuyan entre los diferentes actores jurídicos.

Un punto de partida consistente debería solventar por lo menos dos dificultades, a saber: ¿qué son las RCP? Y, en segundo lugar, ¿por qué nos interesan para aclarar la idea de negociación colectiva?

[Ad 1] Hart no construyó una teoría general de las RCP, ni siquiera delimitó claramente sus contornos. No deseo distorsionar el objeto de este trabajo afrontado cuestiones de tal envergadura. Me parece suficiente para nuestros propósitos la lúcida explicación y definición ofrecida por Atienza y Ruiz Manero y, en este sentido, a ella me remito ${ }^{6}$.

De todos modos, sería conveniente no perder de vista algunos rasgos que caracterizan este tipo de normas. Podríamos aseverar que las RCP presuponen, al menos - de cara a definir sus contornos-, dos afirmaciones complementarias: la primera, ya la hemos enunciado, un sistema jurídico complejo no puede construirse tan sólo por medio reglas respaldadas por amenazas, sino que requiere de ciertas normas, que trasmiten poderes, en general, para regular situaciones en que las normas deónticas no son -expresémoslo de este modo- efectivas. Además, en segundo lugar, las RCP no conllevan una sanción, sino que de ellas se debe predicar, cuando no se usan como es "debido", la nulidad total o la posibilidad de ser anuladas ${ }^{7}$. En este sentido habrá que recordar la diferencia ya clásica establecida por Hart entre nulidad y sanción. Cuando alguien no realiza todos los actos necesarios para dictar un testamento o realizar un convenio colectivo y, por lo tanto, no aparecen los efectos para los que están diseñados, no tiene sentido afirmar que el ordenamiento jurídico los ha sancionado, sino, más bien, habrá que afirmar que sus actos son nulos o anulables ${ }^{8}$.

[Ad 2] A mi juicio, el concepto de las RCP aquilata la virtud de facilitar la comprensión de algunas instituciones jurídicas entre las que se encontraría la negociación colectiva ${ }^{9}$. Además, pueden solventar algunos problemas

${ }^{6}$ Atienza, M. y Ruiz Manero, J., Las piezas del Derecho, Barcelona, Ariel, 1996, pp. 46 y ss.

7 “Al no tener carácter deóntico (no hay conductas calificadas como prohibidas o permitidas), una norma que confiere poder, como tal, no puede infringirse; simplemente, puede usarse bien o mal: si se usan bien, se obtiene el resultado; si no (si se incumple algún requisito) no se obtiene, o no se obtiene del todo, esto es, el resultado no existe o no existe del todo (no es reconocido por el Derecho o no es reconocido del todo) como tal". Atienza, M. y Ruiz Manero, J., Ilícitos atípicos, Madrid, Trotta, 2000, p. 73.

${ }^{8} \mathrm{Al}$ respecto, es relevante la diferencia entre nulidad y sanción. HART. H. L. A., Op. cit., p. 35 y 36 .

${ }^{9}$ El análisis sobre el abuso de derecho, el fraude de ley y la desviación de poder, ofrecido por Atienza y Ruiz Manero o las reflexiones sobre la teoría general de fuentes de Aguiló, ponen 
conceptuales, por ejemplo, diferenciar el proceso jurídico y su resultado institucional, $y$, en definitiva, coadyuvan a distanciarse de una visión atomista de la estructura del ordenamiento jurídico. Esto es, el ordenamiento jurídico no está compuesto por elementos de un único tipo que establecen entre sí un número concreto de relaciones preestablecidas.

De modo más concreto, la relación entre RCP y la negociación colectiva se puede resumir del siguiente modo:

1.- La negociación colectiva no puede ser adecuadamente explicada por medio del concepto de las reglas deónticas, sino que requiere, para su adecuada comprensión, del instrumento conceptual de las $\mathrm{RCP}^{10}$. La negociación colectiva no puede ser reducida a normas deónticas, ni siquiera a un permiso. En el caso de la negociación colectiva, si ésta fuera un permiso que el legislador otorga a los representantes de los trabajadores y de los empresarios, para regular ciertos ámbitos de sus relaciones laborales, sería un sinsentido afirmar que ese permiso ha sido otorgado en los casos en que, por ejemplo, se conculcan determinados derechos laborales por medio del acuerdo o, dicho de otro modo: si entendemos las RCP como meros permisos, se produce la paradoja que éstos pueden ser empleados, indistintamente, de forma lícita o ilícita.

2.- Las RCP no son meras definiciones, y las normas que regulan la negociación colectiva no son sólo definiciones ${ }^{11}$. Si tratamos de explicar los elementos que regulan la negociación colectiva por medio del concepto de definición, se introducen algunas imprecisiones. Por ejemplo, si afirmáramos a) "los convenios colectivos constituyen el acuerdo libremente adoptado por los representantes de los trabajadores y de los empresarios". Esto quedaría bien lejos de sostener que "si los trabajadores y los empresarios metalúrgicos desean modificar sus condiciones laborales deberán realizar tales actos". El primer aserto es una definición, el segundo una RCP; éste último parece que no se puede subsumir, adecuadamente, en el primero. Y, lo que es más importante aún, el concepto de las RCP -como trataremos de mostrar a lo largo de nuestra exposición- parece ser más adecuado para explicar la negociación colectiva y su resultado institucional, convenio colectivo.

Expresado de forma breve: la negociación colectiva sólo puede ser explicada correctamente si la entendemos como un haz normativo, en el cual el concepto de las RCP desempeña un papel fundamental. Efectivamente, tanto

de manifiesto la fuerza descriptiva de este concepto. Atienza, M. y Ruiz Manero, J., Ilícitos atípicos, ed. cit.

${ }^{10}$ Atienza, M. y Ruiz Manero, J., Las piezas del Derecho, cit., pp. 47 y ss.

${ }^{11}$ Atienza, M. y Ruiz Manero, J., Op. cit., pp. 54 y ss. 
estructural como funcional y socialmente, la negociación colectiva puede ser adecuadamente explicada por el concepto de la RCP.

1.- Como es sabido, la estructura de las RCP difiere sustancialmente de la que caracteriza a las normas deónticas. En general, toda norma jurídica está compuesta por un antecedente y un consecuente. En el caso de las norma deónticas, el antecedente es un estado de $\operatorname{cosas}^{12}$, y el consecuente puede ser también un estado de cosas o una acción. Por ejemplo, si se da el estado de cosas X (A es un ser humano y está vivo, y Z le quita la vida), entonces es obligatoria la acción Y para Z (el juez Z está obligado a aplicar la sanción, acción Y). Sin embargo, la estructura de la RCP está formada por un estado de cosas, un sujeto, una acción y un resultado institucional, que es el consecuente. Precisamente, este esquema vertebra la negociación colectiva: si me encuentro ante un problema laboral, cuyo ámbito puede regularse por un convenio colectivo (estado de cosas), y, además, soy un sujeto con capacidad para la negociación (sindicato o representante de los trabajadores) puedo negociar (acción) y, finalmente, se puede producir el resultado institucional, convenio colectivo (consecuente). La estructura canónica de las RCP -y de la negociación colectiva- sería, por tanto:

Si existe un estado de cosas $(\mathrm{X})$ - el sujeto $(\mathrm{Z})$ - realiza la acción $(\mathrm{Y})(\Rightarrow / \Leftrightarrow)^{13}$ se produce el resultado institucional (RI).

2.- La función principal de la negociación colectiva no es establecer una pauta de comportamiento de los trabajadores o de los empresarios, sino que les ofrece la posibilidad de obtener determinados resultados institucionales, en concreto, el convenio colectivo. Con justeza, se ha subrayado que la diferencia principal entre las normas deónticas y las RCP es que las primeras dirigen directamente nuestro comportamiento. En cambio, las RCP no disponen cómo debemos actuar o sólo lo hacen de forma indirecta. Sólo si queremos conseguir determinado resultado institucional, debemos actuar de la forma establecida por las RCP. En este sentido, afirman Atienza y Ruiz Manero que mientras que las normas deónticas son imperativos categóricos, las RCP son imperativos hipotéticos, pues se usan para alcanzar una fina-

12 "Un estado de cosas es un conjunto de hechos naturales y/o institucionales, que, a su vez, pueden o no ser el resultado de acciones naturales o institucionales: por ejemplo, ser mayor de edad y casado es un conjunto de dos hechos institucionales, el segundo de los cuales es, a su vez el resultado de una acción institucional”. Atienza, M. y Ruiz Manero, J., Op. cit., p. 59.

${ }^{13}$ Sobre si ha de ser una condición necesaria, suficiente o necesaria y suficiente ya haremos algunas consideraciones, cuando nos ocupemos de la negociación colectiva en concreto. Por ahora, baste con señalar que me parece correcto el criterio de Ruiz Manero y Atienza, según el cual, RCP son aquellas que "ponen, bien una condición necesaria, bien una condición suficiente, bien una condición necesaria y suficiente de un determinado resultado institucional". Atienza, M. y Ruiz Manero, J., Las piezas del Derecho, cit., pp. 63 y ss. Al respecto cfr. p. 825 , de este trabajo. 
lidad: por ejemplo, si quieres una subida salarial o mejores condiciones de trabajo, entonces debes negociar. Si queremos alcanzar un fin determinado, entonces debemos actuar de una forma concreta.

3.- En definitiva, la negociación colectiva, que se puede estructurar por medio del concepto de RCP, hace posible que se modifique la posición de los agentes o de las otras personas pudiendo influir, de este modo, en su propio interés o en el de los demás. Ésta es, justamente, la finalidad de la negociación colectiva: alterar la relación laboral, ya sea para el bien de las personas que forman parte de la negociación, o bien de terceros que se pueden adherir posteriormente al convenio colectivo.

Por medio de estos planteamientos, se ofrece una primera aproximación a dos interrogantes: qué son las RCP y cuál es su importancia para la negociación colectiva. Como conclusión provisional, que será el punto de partida de este trabajo, podemos sostener que la negociación colectiva se articula por medio de un haz normativo, cuyo núcleo central es una RCP y cuyo resultado institucional es el convenio colectivo. El camino que nos queda por recorrer debe transitar por dos lugares: 1) Analizar los distintos elementos que conforman la RCP y que producen el resultado institucional denominado convenio colectivo, y 2) estudiar la naturaleza jurídica del convenio colectivo.

Aunque, como hemos expuesto, las afinidades entre las RCP y la negociación colectiva son diversas, aquellas que atañen a su estructura nos permitirán avanzar en nuestro trabajo. Así pues, el siguiente esquema funcionará como argumento estructural:

Estado de cosas (E) (competencia funcional, material, ámbito personal, etc.)-Sujeto (Y) (representantes de los empresarios y de los trabajadores)-Acción $(\mathrm{Z})$ (la negociación) $\Rightarrow$ Resultado institucional (R) (Convenio colectivo)

Será importante hacer dos matizaciones más, antes de analizar pormenorizadamente el esquema propuesto:

1.- Es importante subrayar la distinta naturaleza de los elementos que configuran este esquema, pues estas reflexiones establecen un importante punto de partida para nuestra exposición. Como ya se ha señalado (véase la nota a pie 12), el estado de cosas puede estar compuesto, de hecho así sucede en la mayoría de los casos, tanto de elementos naturales como institucionales. Ahora bien, quiénes sean los sujetos legitimados para llevar a cabo la negociación colectiva y qué actos han de realizar no es una cuestión social, ni mucho menos moral, sino jurídico-positiva, es decir, que se establecerá por Ley (Constitución o Ley ordinaria, dependiendo de los casos) quién ostenta estas potestades y qué comportamientos se han de realizar para obtener el resultado institucional. En esta cuestión, el teórico del derecho 
poco tiene que decir. No existe, a mi juicio, una negociación colectiva, al menos tal y como hoy la entendemos, al margen del sistema jurídico; más bien, serán medidas de presión u otro tipo de acuerdos informales, pero no negociación colectiva como tal. Ésta requiere una norma jurídica-del tipo $\mathrm{RCP}$ - que establezca quiénes son los sujetos legitimados, qué acciones se han de llevar a cabo, y bajo qué presupuestos se han de producir para causar determinados efectos jurídicos. Esta aseveración, desde luego, no implica negar el elemento social que, como ha subrayado acertadamente el enfoque sociológico ${ }^{14}$, reside, con particular fuerza, tras la negociación colectiva y que, de forma general, influye sobre todo el fenómeno jurídico.

2.- El esquema propuesto posee la gran virtud de no presuponer el resultado del trabajo o, dicho de otro modo, se adapta tanto a las diferentes teorías que han atribuido al resultado institucional, convenio colectivo, poder normativo, como a aquellas otras que afirman su carácter contractual. Además, es también sensible a la diversidad de productos de la negociación colectiva (pactos de empresa, convenios extraestatutarios o estatutarios, etc.). En estos casos, tan sólo será necesario adaptar los distintos rasgos diferenciadores de cada modalidad negocial. En definitiva, se trata de un auténtico esquema de teoría general del derecho, que, en este sentido, se sitúa allende del dato positivo, pero que, a la par, permite desentrañar algunas de sus dificultades.

Ciertamente, la generalidad del esquema propuesto posee grandes virtudes, pero también causa algunas dificultades. La principal es que por medio de la estructura de las RCP se puede explicar diversas instituciones, por tanto habrá que concretar cuáles son los rasgos distintivos de la negociación colectiva. No en vano, Aguiló, a quien corresponde la autoría y el desarrollo de este esquema, lo ha desarrollado en relación con las fuentes del derecho ${ }^{15}$. Este aspecto ocupa un lugar central también en nuestra exposición, pues, tradicionalmente, una de las grandes polémicas sobre la negociación colectiva es si es una fuente del derecho. Aguiló diferencia entre cuatro categorías de fuentes: fuentes-acto, fuentes-hecho, normas provenientes de la autoridad jurisdiccional y, por último, normas provenientes de la elaboración racional

14 “.... en los cuadros del derecho económico, que corresponden especialmente a los grupos de los obreros productores, se advierte la influencia del esfuerzo común, del trabajo colectivo, favorables a la preponderancia del derecho de la comunidad..." Gurvitch, G., Elementos de sociología jurídica, Granada, Comares, 2001, p. 186.

${ }^{15}$ Como se advierte tras la lectura de las primeras líneas, el presente trabajo es deudor de la obra de Aguiló y de la definición de RCP ofrecida por Atienza y Ruiz Manero. La finalidad de estas líneas es, simplemente, desarrollar el esquema de fuentes propuesto por ellos, dentro del marco de la negociación colectiva. Por eso, es más que recomendable -desde luego, al margen de este trabajo, aún más- para comprender los temas que aquí se ventilan una lectura atenta del trabajo de Aguiló, J., Teoría general de las fuentes del Derecho, Ariel, Barcelona, 2000. Y, por supuesto de Las piezas del derecho. 
del derecho. Las que nos interesan para nuestra finalidad -y ahora acotamos nuestro objeto de estudio- son las primeras, las fuentes acto. De forma general, podríamos definir como fuentes-acto ciertas disposiciones dotadas de eficacia general que son resultado de una competencia determinada ${ }^{16}$. Esto es, un sujeto jurídico, con competencias para ello, realiza una conducta por medio de la cual crea una nueva norma en el sistema jurídico.

Precisamente, esta concreción es la que deseamos llevar a cabo en las siguientes páginas: la negociación colectiva se articula por medio de las RCP $\mathrm{y}$, en determinados casos, puede ser una fuente del derecho, en concreto, una fuente-acto. Habrá, por tanto, que analizar a quiénes se les ha otorgado dichas competencias y en qué circunstancias se puede producir este acto; qué acto/s se han de realizar y, por último, si el resultado institucional aquilata eficacia general. En primer lugar, analizaremos los sujetos de la negociación colectiva.

\section{Los sujetos de la negociación colectiva (Y)}

En principio, la mera determinación de los sujetos de la negociación colectiva plantea múltiples dificultades ${ }^{17}$. Es un lugar común afirmar que los sujetos que han desempeñado estas tareas han sido los representantes de los trabajadores, los empresarios y los representantes de los empresarios. Precisamente, el artículo 37.1 de la CE establece que el legislador garantizará a los "representantes de los trabajadores" y "empresarios" el derecho a la negociación colectiva con efectos vinculantes ${ }^{18}$. De este modo, la determinación legal de los sujetos es un problema jurídico-positivo y no puede ser resuelto, como ya hemos mencionado, a priori, por el teórico del derecho. Además, la legitimación de los sujetos en una RCP conlleva no sólo la determinación de los sujetos, sino también los procedimientos mediante los cuales éstos quedan investidos de autoridad para ejecutar ciertas competencias; por ello, se ha sostenido, con razón, que las fuentes-acto podían ser también denominadas fuentes procedimiento ${ }^{19}$, y estos procedimientos no se establecen en la teoría general del derecho, sino en el derecho positivo ${ }^{20}$.

\footnotetext{
${ }^{16}$ Aguiló, J., Op. cit., p. 75

${ }^{17} \mathrm{El}$ problema no es tan sencillo como se plantea. Se ha expuesto con brillantez cómo, tras la reforma de 1994, se ha llevado a cabo una descentralización de la negociación colectiva. Ello ha implicado que los sujetos que pueden realizar un negocio colectivo sean más numerosos de lo usual y, por tanto, se ha debilitado el carácter de los mismos. Al respecto VaLdÉs DAL RÉ., F., "Notas sobre la reforma del marco legal de la estructura negociación colectiva" en Relaciones Laborales, núm. 5, 1995, p. 30 y ss.

${ }^{18}$ La determinación de los sujetos con legitimación se establece en el Estatuto de los Trabajadores (en adelante, ET).

${ }^{19}$ Aguiló, J., Op. cit., p. 75

${ }^{20}$ RuIz, M., La negociación colectiva como fuente del Derecho, ejemplar multicopiado, p. 24.
} 
A nivel constitucional se debe realizar otra precisión: se ha de poner en relación lo previsto en el artículo 37. 1 CE con el tenor del artículo 28. 1 , donde se recoge la libertad sindical, pues ésta tiene como consecuencia directa el reconocimiento de los sindicatos como sujetos legitimados en la negociación colectiva ${ }^{21}$. Ahora bien, de nuevo hay que matizar que el dato constitucional prevé, de modo general, cuáles son los sujetos que pueden intervenir en la negociación colectiva, pero no cuáles intervendrán en la negociación colectiva, entendida esta como fuente del Derecho.

En este sentido los laboralistas se han escindido en dos grupos:

a) Aquellos que opinan que el artículo 37.1 de la CE contiene una doble norma, esto es, el "precepto constitucional por una parte garantiza el derecho a la negociación colectiva, y por otra, y éste sería un precepto distinto, ordena al legislador ordinario garantizarlo"22. De este modo, habría dos tipos de convenios colectivos, aquellos que podrían ser desarrollados siguiendo lo previsto en el Estatuto de los trabajadores (llamados usualmente estatutarios), y otros que provendrían de forma directa del mandato constitucional y que no cumplirían alguno de los requisitos - principalmente, aquellos referentes a sujetos activos, publicación, etc.- establecidos en el ET.

b) Existen otros autores que sostienen que el mandato constitucional es único y que, por tanto, el artículo 37. 1 no garantiza de por sí el derecho a la negociación colectiva; este artículo no es un "estatuto completo". Estos autores afirman que la letra del mandato constitucional es clara "la ley garantizará el derecho a la negociación colectiva laboral (...)”. Será, por tanto, el legislador ordinario quien garantice el derecho a la negociación colectiva ${ }^{23}$.

Aunque esta polémica no está exenta de interés por sus consecuencias prácticas $^{24}$, sólo queremos destacar, por ahora, que ratifica nuestra aproxi-

\footnotetext{
${ }^{21} \mathrm{Al}$ respecto se puede consultar la STCo 118/83 de 13 de diciembre, donde se reconoce la libertad sindical exclusivamente a las organizaciones sindicales. Más recientemente en la STCo 95/96 de 29 de mayo se afirma que los sindicatos son creación constitucional, los comités de empresa y delegados de personal son creación de la Ley. Además, si atendemos a la realidad la mayoría de los convenios colectivos tienen un origen sindical. Cfr. Escribano, J., Autonomía individual y colectiva en el sistema de fuentes del Derecho del Trabajo, Madrid, CES, 2000, p. 245.

${ }^{22}$ La cita es de DurÁn López, F., "El estatuto de los trabajadores y la negociación colectiva" en Revista Laboral, 1990- II p.130. Una defensa de estos argumentos se encuentra, por ejemplo, en Correa CARrasco, M., La negociación colectiva como fuente del derecho, Madrid, Universidad Carlos III. BOE, 1997, pp. 254 y ss.

${ }^{23}$ Durán López "El estatuto de los trabajadores y la negociación colectiva" en Revista Laboral, 1990- I, p. 137.

${ }^{24}$ En el primer supuesto, hay que tener en cuenta que el convenio extraestatutario se podría imponer a los trabajadores con independencia de su voluntad. Desde la segunda perspectiva, tendrá que ser incorporado al clausulado del contrato del trabajador. En el fondo, la estructura completa del artículo 37. 1 es un haz normativo complejo que contiene al menos: 1.- Un per-
} 
mación a los sujetos del derecho, como autoridades instituidas por medio de un procedimiento concreto. Esto es, lo que los laboralistas están discutiendo es si el mandato constitucional hace referencia a una o dos RCP. Aquellos que optan por la duplicidad del mandato sostienen que en la CE se encuentran dos RCP: una a nivel constitucional, que otorga a determinados sujetos la capacidad de crear un resultado institucional (convenio colectivo extraestatutario), y otra a nivel legal, que otorga a determinados sujetos la posibilidad de crear un resultado institucional con efectos vinculantes (convenio colectivo estatutario). Los que apuestan por el mandato único creen que sólo cuando se cumplen los requisitos previstos en el ET, se producirá un convenio colectivo; cuando esto no se produzca, estos acuerdos tendrán la fuerza de meros contratos. Esto supone que, al igual que ocurre con otro tipo de fuentes acto, dependiendo de la autoridad que ostenten los sujetos legitimados ${ }^{25}$, podrán producir un resultado institucional u otro o, lo que es lo mismo, si un sujeto legitimado emplea distintos procesos para dotarse de autoridad, el resultado institucional variará. Podríamos resumir lo expuesto hasta ahora del siguiente modo:

1.- La discusión entre los laboralistas ratifica nuestro esquema; ellos tan sólo se preguntan sobre el número de RCP al que hace alusión el mandato constitucional.

2.- Al igual que sucede en las otras fuentes-acto, los mismos sujetos, ya sea por procedimientos distintos o bien porque ejercen una autoridad distinta, pueden crear resultados institucionales que, dependiendo del caso, pueden poseer eficacia general o un tipo de fuerza más limitada ${ }^{26}$.

3.- La autoridad para llevar a cabo los convenios colectivos depende de los sujetos y de los procedimientos que éstos sigan.

Aunque la determinación de los sujetos con representatividad suficiente para llevar a cabo la negociación colectiva es una cuestión positivo-jurídica,

miso para aplicar una RCP. 2. Una RCP que no se establece en la propia Constitución, sino cuyos elementos se encuentran dispersos en el ET. 3.- Una disposición deóntica que obliga al legislador a regular la negociación colectiva. El núcleo de nuestro trabajo se encuentra, como ya hemos señalado, en el análisis del segundo elemento.

${ }^{25}$ El artículo 85 del ET contiene la expresión “sujetos legitimados para negociar". Posiblemente, hubiera sido más correcto utilizar la expresión "sujetos capacitados" o "sujetos con competencia para negociar convenios colectivos".

${ }^{26}$ Aguiló cita el siguiente ejemplo: "la diferente autoridad entre una resolución aprobada como conclusión de un debate parlamentario y una ley aprobada como consecuencia de su tramitación parlamentaria no radica en los sujetos que han llevado a cabo la aprobación parlamentaria (en ambos casos se trata del mismo sujeto), sino en el procedimiento seguido". AguiLó, J., Op. cit., p. 73. Igual sucede con el convenio colectivo, pues es posible que los mismos sujetos sigan el procedimiento previsto en el Título III del ET y entonces el resultado institucional sea el convenio colectivo, o bien que actúen, en algún u otro modo, al margen de él, y, entonces, el resultado tenga la mera fuerza de un contrato. 
implica, inevitablemente, una política-jurídica. Antes de la reforma de 1980 el espíritu de la negociación colectiva estaba insuflado por los siguientes principios: a) principio de neutralidad, es decir, el legislador permitía que las partes eligieran el nivel de negociación más adecuado para sus intereses; b) principio de igualdad de trato entre los diferentes niveles contractuales, que se traducía en iguales capacidades normativas para los distintos sujetos, c) por último, se establecía un sistema de resolución de conflictos, basado en ciertas reglas, que resolvían la concurrencia de varios convenios sobre una misma materia. Pues bien, la posterior reforma de 1994, en referencia a los sujetos de la negociación colectiva, ha producido el abandono del "anterior y por tantas razones loable principio del laissez faire colectivo, el nuevo ET ha venido a implantar fórmulas de dirigismo contractual que transparentan de modo neto la preferencia hacia determinados niveles de negociación"27.

Efectivamente, debido a la multiplicación de los sujetos que pueden intervenir en la negociación colectiva, hay una pérdida de la fuerza de ésta como fuente del derecho. De esta suerte, la inclusión del comité de empresa para intervenir en los pactos de empresa que, por medio del principio de modernidad $^{28}$, pueden modificar el convenio colectivo de ámbito superior, conlleva la posibilidad de reducir la fuerza de un convenio establecido por otros sujetos. Por ahora, baste con precisar que, al igual que sucede con otras fuentes-acto, cuando los sujetos que pueden crear el resultado institucional se incrementan, sus resultados institucionales se "cantonalizan" y, por tanto, sus contornos se aproximan más a los del contrato. De este modo, paradójicamente, cuando el Estado reconoce a un mayor número de sujetos la capacidad de negociación colectiva, menor fuerza ejercerán sus resultados.

Por tanto, como ya hemos señalado, quiénes -y cuántas- sean las autoridades depende también de los procesos que se establecen para su determinación. Lógicamente cuanto mayor es el número de autoridades que pueden producir el resultado institucional, más complejos serán los procedimientos

${ }^{27}$ VALDÉs DAL- RÉ, F., "Notas sobre la reforma del marco legal de la estructura de la negociación colectiva" cit p. 28.

${ }^{28}$ En principio, no se puede producir la concurrencia de dos convenios colectivos, es decir, un convenio colectivo no puede ser afectado por lo dispuesto en otros. Sin embargo, el art. 84 del ET, en su inciso segundo, dispone: "En todo caso, a pesar de lo establecido en el artículo anterior, los sindicatos y las asociaciones empresariales que reúnan los requisitos de legitimación de los artículos 87 y 88 de esta Ley podrán en un ámbito determinado que sea superior al de empresa negociar acuerdos o convenios que afecten a lo dispuesto en el ámbito superior siempre que dicha decisión obtenga el respaldo de las mayorías exigidas para constituir la Comisión Negociadora en la correspondiente Unidad de Negociación". El complejo tenor de este artículo puede resumirse en que, siempre que se den los requisitos establecidos en él, el convenio más moderno deroga al más antiguo, aunque aquel se haya negociado en un ámbito superior. Esto, desde luego, resta fuerza al convenio. 
de su determinación, así como la relación -en este caso, la jerarquía- entre los diferentes productos institucionales, resultantes de la actividad de cada una de estas autoridades.

Además, desde el punto de vista de los sujetos con suficiente representatividad, se colige una importante consecuencia que nos ayuda a dibujar los contornos del convenio colectivo. Si los sujetos quedan reducidos a una minoría, el convenio colectivo se asemeja a las fuentes-acto. Sin embargo, si los sujetos son muchos, el convenio colectivo pierde eficacia y se parece más a una fuente de obligaciones. En los casos extremos, tanto cuando el sujeto con representatividad suficiente es uno sólo -sindicato vertical-, como cuando los sujetos son demasiados - tal vez la situación que se viene produciendo desde las últimas reformas laborales-, el convenio colectivo termina perdiendo su carácter propio y asemeja sus rasgos a los del contrato. Expresado de modo breve, si existe un único sujeto con representatividad suficiente para llevar a cabo el proceso de negociación colectiva, el resultado institucional se asemeja, desde el punto de su eficacia-erga omnes- y de los sujetos que lo llevan a cabo, tanto a las fuentes-acto que pierde su carácter de negociación colectiva. $\mathrm{Si}$, a la inversa, los sujetos con capacidad suficiente son demasiados, el resultado institucional se asemeja -pues su eficacia se reduce de modo drástico- tanto a las fuentes de obligaciones que pierde, del mismo modo, su carácter propio. Parece pues, que entre estos dos casos extremos se puede producir una negociación colectiva, cuyo más típico resultado institucional es el convenio colectivo.

No obstante, si atendemos al criterio de los sujetos con representatividad suficiente, existen algunas concomitancias entre la negociación colectiva y otras fuentes-acto creadas por las autoridades políticas. Éste es el caso del límite mínimo de representatividad. El ET establece un diez por ciento de representación, como cuota mínima que han de tener los sindicatos para representar a los trabajadores. Este criterio tiene una finalidad parecida a aquel otro límite, establecido para los grupos parlamentarios en algunos países como, por ejemplo, en la República Federal Alemana. Ambos tratan de producir cierta estabilidad en la creación de los resultados institucionales, llevados a cabo por estos sujetos. Aunque se ha querido interpretar este límite como una posible inconstitucionalidad del ET, pues contravendría el derecho a la negociación colectiva de ciertos sujetos, otro sector doctrinal, apoyándose en decisiones jurisprudenciales, ha puesto de manifiesto que se trata de una consecuencia directa de la formalización, a la que ha sido sometida la negociación colectiva en nuestro país ${ }^{29}$.

${ }^{29}$ DurÁn LóPEZ, F., Op. cit., p. 143. Además, sostiene que "lo que no tiene sentido es decir que esto es inconstitucional, pero que como los sindicatos excluidos pueden celebrar convenios 
Una última reflexión, respecto a los sujetos que pueden llevar a cabo la negociación colectiva, debe referirse, aunque sea de forma breve, a la autonomía colectiva. Se podría afirmar que, desde un punto de vista iusfilosófico, la autonomía colectiva es el fundamento que faculta a los sujetos para llevar a cabo la negociación colectiva. Esto es, la autonomía colectiva funciona como un valor jurídico que, posteriormente, se ha de institucionalizar dando lugar a diferentes facultades de los sujetos colectivos (negociación colectiva, derecho de huelga, derecho a la sindicación, etc.). De ahí que la doctrina iuslaboralista ha puesto especial atención en señalar las diferencias entre el valor -autonomía colectiva- y las diferentes normas, principios o instituciones que se desprenden de ella. Por tanto, la autonomía colectiva no puede reducirse a un mero contrato de mandato, de representación ni de delegación ${ }^{30}$. Obviamente, sostener que algo -en este caso la autonomía colectiva- es un valor jurídico, no significa sostener que las autoridades jurídicas crean estos valores, sino que, para nuestro análisis, "son interesantes únicamente los valores asumidos por las autoridades jurídicas" "31. Este aserto se compagina bien con la idea, expuesta anteriormente, de que la autonomía colectiva es, a la par, un producto social y legal.

Creo que hay que diferenciar, pues, entre dos aspectos: una cosa es el mecanismo jurídico por el que se reconoce la autonomía colectiva en un ordenamiento jurídico, y otra, muy distinta, la naturaleza social de ésta; expresado de otro modo: la autonomía colectiva es un elemento sociológico -pero, además también jurídico- que, a mi juicio, no puede reducirse al esquema explicativo de un contrato de mandato o a una delegación del legislador; ni siquiera parece que pueda ser explicado por el mismo esquema de la participación política de la sociedad civil, a través de sus representantes parlamentarios. Sin embargo, la determinación de los sujetos que han de llevar

colectivos al margen de lo previsto en la Ley, puede salvarse la constitucionalidad de la misma". Cita este autor la STCo 73/1984 de 27 de junio, que avala el modelo de representación establecido en el ET.

${ }^{30}$ Los iuslaboralistas han defendido fundamentalmente tres teorías: 1.- Hay quienes han sostenido que la autonomía colectiva ostenta un carácter originario, por lo que el Estado se limitaría a reconocer un poder normativo ajeno a él. Esta teoría, que fue desarrollada, desde el punto de vista sociológico, por Gurvitch y que se apoya en el institucionalismo de Santi Romano, fue defendida por Lyon-Caen, en el ámbito del derecho laboral. 2.- Otros han querido encontrar en la figura del mandato el puente que unía la negociación colectiva con la autonomía colectiva, pues los trabajadores realizan un acto de renuncia de sus poderes a favor del grupo sindical que les representa. 3.- Por último, otras parten del carácter delegado del convenio colectivo, un poder delegado por el Estado, en concreto, por medio de la Constitución. Aunque ésta postura se ha criticado por algunos autores que han sostenido que el convenio colectivo no requiere el auxilio de la Ley para tener eficacia. EsCRIBANo, J., op. cit., p. 51 y ss. Una defensa de la teoría de la delegación puede encontrase en Correal Carrasco, M., Op. cit., p. 162.

${ }^{31}$ Atienza, M., Ruiz Manero, J., Las piezas del Derecho, cit., p. 138. 
a cabo un proceso jurídico concreto para producir un resultado institucional es un mecanismo jurídico, que nace dentro del propio sistema jurídico, por medio de delegación del Estado, y que tiene presente el valor jurídico de la "autonomía colectiva". Desde luego esta afirmación no dificulta el reconocimiento de la autonomía colectiva, más bien, lo ratifica. De esta suerte, el reconocimiento de los sujetos es un símbolo, una huella de la autonomía colectiva en el sistema jurídico, pero no la causa de la existencia de los sujetos legitimados; ésta es, a mi juicio, de naturaleza jurídico-positiva.

\section{El estado de cosas (E)}

El estado de cosas es aquel conjunto de hechos o actos, institucionales o naturales, que constituyen una parte del antecedente de la RCP (véase nota12). Existe una gran diversidad de razones operativas que permanecen fuera del estado de cosas y que, de ordinario, pueden acompañar al proceso de negociación colectiva: problemas laborales, deseo de mejorar las condiciones laborales, recorte de presupuesto de la empresa, etc. Un análisis del estado de cosas de la negociación colectiva, sin embargo, requiere, al menos, del examen de los siguientes elementos:

a) Las competencias materiales

b) Ámbito territorial

c) Ámbito personal

d) Ámbito funcional

a) Ámbito material. Tradicionalmente se ha sostenido que el convenio colectivo es la ley del ámbito profesional, por tanto, regulará todas aquellas materias que pertenezcan a éste. Durán López ha escrito que, aunque la negociación colectiva debe adaptarse a aspectos laborales, estos no clausuran las materias que se pueden llevar a cabo por medio de ella ${ }^{32}$. Los sujetos legitimados para realizar la negociación colectiva determinarán cuál será el ámbito de la negociación colectiva y las materias sobre las que ésta versaráa ${ }^{33}$.

Una lectura del artículo 37 de la CE pone de manifiesto la amplitud y la generalidad de este precepto. Será a nivel legal donde se plasme qué materias se pueden regular por medio de la negociación colectiva. El antiguo artículo 85 del ET extendía el ámbito de la negociación colectiva al amplio campo de las "materias de índole económica", excluyendo ciertas "materias de carácter asistencial". Sobre ciertos aspectos no se puede negociar, salvo que lo dispongan normas de carácter absoluto ${ }^{34}$.

\footnotetext{
32 Durán LóPez, F., "El estatuto de los trabajadores y la negociación colectiva", cit. p. 121.

${ }^{33}$ Ruiz, M., Op. cit., p. 26

${ }^{34}$ Alonso Olea, M., y Casas Baamonde, M. E., Derecho del Trabajo, Madrid, Civitas, 2000, p. 904 y ss.. De todos modos, ciertas materias quedan excluidas por su naturaleza de
} 
b) Ámbito territorial y funcional. La determinación de ambos es un requisito ineludible, ex lege, que han de contener los convenios colectivos. Serán los propios sujetos del convenio quienes especifiquen cuál será el ámbito territorial y funcional de los convenios colectivos. Por tanto, dependiendo del tipo de sujeto de que se trate, se determinará la extensión del convenio colectivo. Para realizar un pacto en el ámbito de la empresa será suficiente con que los sujetos sean los representantes de los trabajadores y del empresario. Este aspecto es también una especificidad del convenio colectivo, pues el contenido del mismo determinará la extensión de sus efectos y qué funciones laborales regulará.

c) Ámbito temporal. He aquí, de nuevo, una peculiaridad propia del convenio colectivo. Los sujetos pueden y, es más, deben establecer cuándo entrará en vigor el convenio colectivo y cuándo cesarán sus efectos. En él ha de constar $-\mathrm{y}$ esta es una característica establecida ex lege $e^{35}$ la forma y las condiciones de la denuncia del convenio colectivo. Esta necesidad se halla íntimamente relacionada con la naturaleza temporal del convenio colectivo; se desea obtener un acuerdo para un momento determinado. Uno de los rasgos definitorios del convenio colectivo es la labilidad de las relaciones reguladas, ya que las condiciones laborales pueden modificarse con cierta rapidez; sería imposible que se realizará un convenio colectivo destinado a perdurar en el tiempo, pues las circunstancias que provocaron su nacimiento están destinadas a modificarse por el devenir socio-económico.

\section{El acto de la negociación (Z)}

Hasta el momento tan sólo hemos analizado dos de los componentes fundamentales de la negociación colectiva, cuyo resultado institucional es el convenio colectivo u otros resultados institucionales, según los casos. Estos dos elementos, estado de cosas y sujetos, han sido expuestos lacónicamente, pues analizarlos en profundidad es una meta demasiado ambiciosa para los propósitos y objetivos de este trabajo, los cuales no son otros que clarificar, por medio de la estructura propuesta, algunos caracteres de esta institución jurídica. No se trata, pues, de realizar una exposición pormenorizada de los elementos y procedimientos jurídico-positivos que han de concluir en los distintos productos negociales.

Ahora debemos esbozar, del mismo modo, algunos de los problemas y dificultades que entraña otro de los elementos de la RCP: el acto. Éste

ius cogens, como es el caso de la seguridad social, sobre la que tan sólo se pueden negociar mejoras, pero no se puede modificar in peius, es decir, funciona como una norma mínima sobre la que se puede partir para negociar mejoras.

${ }^{35}$ Cfr. Art. 85.3 ET. 
esquematiza uno los ejes principales en torno a los cuales gira el proceso de la negociación colectiva. Los actos o conjunto de actos que han de ser realizados por los sujetos para obtener un producto institucional que, según los casos, puede o no tener fuerza vinculante, están regulados por Ley, en concreto, por el ET. De esta suerte, se ratifica la afirmación de que la negociación colectiva es un producto legal y no social, siempre y cuando la observemos desde el punto de vista del teórico del derecho o del jurista ${ }^{36}$.

De forma sucinta podemos resumir estos actos del siguiente modo. En un primer momento, se debe realizar una comunicación de la negociación que contendrá, como elementos obligatorios, los "sujetos con legitimación para negociar", el ámbito de la negociación y la materia objeto de la misma. Posteriormente, se formará una comisión negociadora del convenio colectivo, designada por los sujetos, ya mencionados anteriormente (véase p. 810). El derecho a la constitución de la comisión negociadora se fundamenta en el derecho a la sindicación y, por tanto, está protegido constitucionalmente por medio del artículo 53.2.

De esta exposición se desprende una pregunta, cuya respuesta puede modificar, en buena medida, nuestro análisis: ¿quiénes son los auténticos sujetos de la negociación, los representantes de los trabajadores y el empresario o, más bien, aquellos otros que forman parte de la comisión negociadora? Alonso Olea sostiene que "en términos negociales podría decirse que la legitimación inicial es legitimación para nombrar a los representantes (en convenios empresariales e infra-empresariales generales) y para acceder mediante representantes (en convenios supra-empresariales) a la comisión negociadora y allí negociar"37. Así pues, ¿qué relación existe entre los sujetos que poseen la legitimación para negociar y aquellos otros que forman la comisión negociadora? ¿Existe un mandato o una delegación? ¿Quiénes son los auténticos sujetos que producen el resultado institucional? Comenzando por responder la última de nuestras preguntas: creo que no es necesario modificar nuestro esquema explicativo. A mi juicio, los sujetos que producen el resultado institucional son tanto los reconocidos de forma

\footnotetext{
${ }^{36}$ Hipotéticamente, sería posible un acuerdo entre los trabajadores para elegir algún representante que, a su vez, negociará con el empresario ciertas condiciones de trabajo, y que este proceso concluyera en un acuerdo en el que no hubieran intervenido el sistema jurídico. Pero las posibilidades de que este tipo de acuerdos se produzcan en la realidad son mínimas. No se debe eludir el dato estadístico que subraya el carácter sindical de los convenios y, por tanto, su contacto con el ámbito legal, ya que el sindicato es una institución creada por medio de mecanismos jurídicos, en concreto, regulado por medio de la Ley Orgánica 11/1985, de 2 de agosto, de libertad sindical (BOE núm. 189, de 8 de agosto de 1985). Sobre el carácter mayoritariamente sindical de los convenios cfr. Escribano, J. Op. cit., p. 245 y ss.

${ }^{37}$ Alonso Olea, M. y Casas Baamonde, M. E., Derecho del Trabajo, cit., p. 857.
} 
general en el artículo 37.1 de la CE, como aquellos que conforman la comisión negociadora, es decir, para que se produzca el resultado institucional es obligada la actuación tanto de unos como de otros. Podríamos sostener que existe una $\mathrm{RCP}_{2}$, cuyos sujetos son los legitimados en el artículo 37.1 y cuyo resultado institucional es conferir poderes a otros sujetos para que los representen en la comisión negociadora. La relación de los sujetos con "legitimación general" y aquellos que forman la comisión negociadora es de causa-efecto: sin el consentimiento de los primeros no se pueden formar los segundos, aunque, desde luego, representan diferentes realidades ${ }^{38}$. No creo que sea correcto sostener que la comisión negociadora es el auténtico sujeto que lleva a cabo la negociación colectiva. Aunque es obvio que existen importantes diferencias con las fuentes-acto, aprobadas por autoridades políticas, defender esta tesis sería, mutatis mutandi, afirmar que la comisión que redacta una ley es el auténtico sujeto del acto y no los grupos parlamentarios que la aprueban.

\section{El resultado institucional: convenio colectivo}

Hay que advertir que de este proceso, que hemos descrito sumariamente, nacen distintos productos institucionales que no pueden reducirse al convenio colectivo regulado en el ET, sino que, además, nos podemos hallar, según los casos, ante acuerdos extraestatutarios -cuando no se han observado los requisitos establecidos en el ET-, o bien frente a simple pactos de empresa -si estos acuerdos han sido aprobados en sede empresarial-. Aunque no nos es desconocida la variedad de resultados institucionales en que puede concluir el proceso negocial, nos centraremos en los llamados convenios colectivos estatutarios, pues la doctrina les otorga usualmente el rasgo de normatividad.

Antes de analizar el resultado institucional se debe afrontar una cuestión previa: la relación existente entre el antecedente de esta norma y su consecuente. Para ello es preciso realizar una lectura atenta del artículo 37.1 de la CE. Allí se establece una garantía constitucional para que se pueda producir la negociación y, en el caso de que finalmente se produzca un acuerdo, entonces se garantiza la fuerza vinculante de su resultado, es decir, no hay una relación de causa-efecto entre el derecho a negociar y la elaboración del convenio colectivo; puede ser que la negociación llegue a buen puerto, pero también es factible que no se plasme en acuerdo alguno ${ }^{39}$. Pero esta

\footnotetext{
${ }^{38}$ Sobre la diferencia de estos sujetos se puede consultar la sentencia STC de 17 de octubre de 1986, donde se reconoce la existencia de un mandato, el cual comienza con la designación de esta comisión y concluye con la firma del convenio o con la ruptura de la negociación.

${ }^{39}$ Durán lo ha expresado con las siguientes palabras: "la Constitución prevé la garantía legal del derecho a la negociación colectiva, porque no puede prever el derecho a obtener o
} 
afirmación no dificulta ni deslegitima nuestro esquema explicativo, pues, como sostienen Atienza y Ruiz Manero, las reglas que confieren poderes son reglas que "ponen, bien una condición necesaria, bien una condición suficiente, bien una condición necesaria y suficiente de un determinado resultado institucional" ${ }^{40}$. En el caso de la RCP que articula el proceso de la negociación colectiva, sería realmente difícil establecer todos los elementos de tal forma que estableciera una RCP completa. Esto significa que el proceso negocial puede concluir, lógicamente, de dos modos:

a) Cuando la negociación no llega a buen puerto, y no se establece ningún acuerdo.

b) El proceso puede concluir fructíferamente, si se llega a producir un convenio colectivo $-\mathrm{u}$ otro resultado institucional-.

En el primer supuesto, cuando la negociación fracasa, suele seguir en vigor, si lo hubiere, el convenio anterior. En el segundo caso, es necesario que se respeten una serie de requisitos formales (conclusión por escrito del pacto final, remisión a la autoridad laboral, depósito y publicación $)^{41}$.

El siguiente esquema facilita una recapitulación de los argumentos expuestos:

$\mathrm{H}_{1}, \mathrm{H}_{2}, \mathrm{H}_{3}, \ldots, \mathrm{H}_{\mathrm{n}}$-Convenio colectivo- $\mathrm{C}_{1}, \mathrm{C}_{2}, \mathrm{C}_{3}, \ldots \mathrm{C}_{\mathrm{n}}^{42}$

En nuestra exposición, hasta ahora nos hemos centrado en la parte izquierda del esquema, es decir, hemos tratado de enumerar cuáles son los hechos -empleando este término en un sentido muy amplio- $\left(\mathrm{H}_{1}, \mathrm{H}_{2}, \mathrm{H}_{3} \ldots, \mathrm{H}_{\mathrm{n}}\right)$, que producen las consecuencias $\left(\mathrm{C}_{1}, \mathrm{C}_{2}, \mathrm{C}_{3}, \ldots \mathrm{C}_{\mathrm{n}}\right)$. Ahora es, pues, el momento de pasar a centrarnos en qué consecuencias jurídicas provocan estos hechos. Ahora analizaremos la consecuencia principal, que se obtiene cuando se han producido determinados hechos o actos institucionales, o no: la eficacia del convenio. Por ello, el convenio colectivo - u otro tipo de pacto- en sí no es

conseguir convenios colectivos. Sólo prevé, por consiguiente, el derecho a negociar, para lo cual podrán establecerse los procedimientos correspondientes, y si en el caso de la negociación se llega a conseguir un acuerdo, si la negociación fructifica en un convenio, éste ha de tener, conforme al mandato constitucional, fuerza vinculante. Se trata, por tanto, de dos momentos distintos del mismo proceso lógico, y no de la consagración constitucional de dos cosas distintas". DurÁn López, F., Op. cit., p. 137

${ }^{40}$ Aunque como exponen estos autores hay distintas clasificaciones de este tipo de reglas. Cfr. Atienza, M. y Ruiz Manero, J., Las piezas del derecho, cit. p. 63 nota 8.

${ }^{41}$ Cfr. art. 90.3 del ET.

${ }^{42}$ El bosquejo está tomado, como se puede advertir, del análisis de la propiedad privada realizado por Ross, A., Sobre el Derecho y la justicia, Buenos Aires, Eudeba, 1994, p. 166. Aunque obviamente no se puede hacer un paralelismo completo con la explicación proporcionada por Ross en relación con la propiedad privada, ya que para él las normas jurídicas deben ser interpretadas como "directivas dirigidas al juez". Sin embargo, pensamos que, teniendo en cuenta esta importante salvedad, el esquema de Ross ofrece claridad a nuestra exposición. 
"nada", simplemente es un nomen iuris, una herramienta que asocia unos hechos con consecuencias jurídicas; por ello, su análisis pasa por estudiar unos y otras.

\section{La eficacia del convenio colectivo}

Se ha expuesto cómo el convenio colectivo o el resultado institucional del proceso denominado negociación colectiva se ajusta, sin demasiadas dificultades, al esquema propuesto por Aguiló para explicar las denominadas fuentes-acto. Ahora bien, aún se deben afianzar las últimas premisas de este argumento, que son de especial importancia. Efectivamente, "no todo acto jurídico que consiste en el ejercicio de una competencia es una fuente-acto"43. Tendrá que poseer eficacia general, esto es, "...la eficacia general, es la que explica por qué suele decirse que el resultado de la fuentes-acto es un documento normativo, publicado oficialmente y dotado de autoridad. La eficacia general de las fuentes-acto exige no que el resultado sea comunicado a los interesados como ocurre con muchos otros actos jurídicos, sino que sea hecho público"44. Creo que es interesante retener en la memoria estas ideas a la par que reflexionamos sobre si del convenio colectivo se puede predicar el atributo de la eficacia.

Un punto de partida es el, ya citado en tantas ocasiones, art. 37. 1 de la CE. En él se sostiene que "la ley garantizará el derecho a la negociación colectiva laboral entre los representantes de los trabajadores y empresarios, así como la fuerza vinculante de los convenios". Por tanto, si la ley garantiza la fuerza vinculante habrá que aclarar cuál es el procedimiento que, según el legislador ordinario, se ha de seguir para que el resultado institucional sea vinculante. Pero este camino no nos conduce demasiado lejos, pues que el resultado sea vinculante, en puridad, no nos aclara nada, también se afirma de las negocios jurídicos que lo establecido en ellos tiene fuerza vinculante para las partes, e incluso se habla de "lex privata" 45 para los sujetos. Tampoco, a mi juicio, es correcta la hipótesis según la cual el convenio colectivo es

${ }^{43}$ Aguiló, J., Op. cit., p. 72

${ }^{44}$ Aguiló, J., Op. cit., p. 74-5

${ }^{45}$ De Castro, F., El negocio jurídico cit., p. 32. En este sentido, el artículo 1091 de nuestro Código civil afirma "que tiene fuerza de ley entre las partes contratantes". También Kelsen advierte: "este acto es un hecho productor de normas jurídicas, en tanto y en cuanto el orden jurídico otorgue a ese hecho esa calidad, y se la otorga en tanto hace de la realización del hecho del negocio jurídico, junto con una conducta contraria a él, condición de una sanción civil". Vid. Kelsen, H., Teoría pura del derecho, México, Ed. Porrua, 1991, pp. 264-5. Esto significa, simplemente, que lo dispuesto en el negocio jurídico vincula a las partes, a mi juicio, el negocio jurídico no es una fuente del Derecho por las razones expuestas más arriba, es decir, carece de eficacia general. 
vinculante por naturaleza, y la Constitución lo único que hace es reconocerla ex post ${ }^{46}$.

Resumiendo podríamos afirmar que los iuslaboralistas sostienen principalmente dos posturas respecto de la vinculatoriedad del convenio:

1.-Aquellos que creen que el convenio colectivo despliega sus efectos al margen de los desarrollos legislativos, directamente desde la Constitución, y que éste no hace más que plasmar un sistema de pluralismo jurídico, que encuentra su base en las necesidades sociales

2.- Aquellos que opinan que el legislador constitucional ha creado tan sólo una garantía institucional de la negociación colectiva, que será desarrollada por el arbitrio del legislador ordinario y que tiene como único límite el respeto a un espacio donde se pueda crear la intervención heterónoma y la eficacia de lo negociado ${ }^{47}$. El fundamento principal de los autores, que defienden está segunda tesis, es que tan sólo la CE tiene competencia legal para determinar bajo qué condiciones los diferentes convenios colectivos pueden integrarse en el sistema de fuentes, si esto se determinara por ley ordinaria "significaría atribuir a la ley la potestad de distribuir poderes normativos, algo que le estaría absolutamente vedado"48.

A mi juicio, creo que es la ley quien otorga la fuerza a los convenios; en este sentido, la literalidad del artículo 37. 1 de la CE no deja lugar a dudas. También hay que tener en cuenta que la Constitución no sólo define derechos subjetivos, sino que "además sirve para fijar el margen de discrecionalidad de que dispone el legislador ordinario"49.

${ }^{46}$ En este sentido, Correa CARrasco sostiene que "la negociación colectiva, en tanto que manifestación directa de un poder social originario, gozará de una relevancia ordenadora que dependerá, en principio, de factores exógenos al sistema jurídico material”. Tan sólo, posteriormente, se plasmará ese poder en la CE que, para este autor, parece tener un cierto matiz entre jurídico y social; en este sentido escribe: “en conclusión, cualquier tipo de convenio tiene su fundamento último en el artículo 37. $1 \mathrm{CE}$ y, en consecuencia, la fuerza vinculante se predica de todo producto negocial, y no sólo del diseñado por ley". Correa CARrasco, M., La negociación colectiva como fuente del derecho del trabajo cit., pp. 93 y 263, respectivamente.

${ }^{47}$ Ruiz Castillo, Op. cit., p. 28. Tengo la intuición, dicho esto con la mayor de las cautelas, que estas dos miradas, arrojadas por los iuslaboralistas sobre la eficacia del convenio colectivo, representan dos perspectivas distintas. Los primeros no analizan qué es la negociación colectiva, sino que "debería ser". Los segundos sólo tienen en cuenta el dato positivo sin percibir de dónde procede. En descargo de los primeros, habría que subrayar que el sistema jurídico tiene relaciones con otros sistemas como, por ejemplo, el social. En defensa de los segundos, que para definir si una institución jurídica ostenta determinados rasgos no es preciso acudir fuera del sistema jurídico.

${ }^{48}$ Correa Carrasco, M., Op. cit., p. 293. Obviamente, la ley ordinaria, en este caso concreto el ET, no distribuye las potestades normativas; es el propio precepto constitucional el que establece la delegación.

${ }^{49}$ Ruiz Castillo, M., Op. cit., p. 28. También Durán, F., loc. cit. p. 140. 
Como conclusión de carácter general, se podría sostener que la mayoría de la doctrina defiende la eficacia de todos los convenios que han seguido los requisitos establecidos en el Título III del ET. Los problemas se plantean, como ya se ha mencionado, respecto a los llamados convenios extraestatutarios, es decir, aquellos que carecen de alguno de los requisitos establecidos en el ET.

Hasta ahora hemos expuesto las distintas teorías sobre la fuerza vinculante de los convenios, pero no nos hemos detenido en el significado de este término. Para los laboralistas existe una equivalencia entre fuerza vinculante y eficacia. Y la eficacia posee, al menos, dos acepciones: eficacia vertical, que es aquella que despliega el convenio colectivo como norma jurídica sobre la relación de derecho del trabajo, y eficacia horizontal, por medio de la cual se reserva un ámbito de regulación propio frente a las normas de carácter estatal ${ }^{50}$. Centrémonos en el primer tipo de eficacia.

A su vez, la eficacia vertical se desglosa en "eficacia real" y la denominada "eficacia normativa". La primera de ellas surte tres efectos de gran importancia: a) efecto automático, que significa que las cláusulas contractuales han de ser reemplazadas si son contrarias a lo previsto en el convenio colectivo; b) efecto inderogable, esto es, que el convenio colectivo no puede ser derogado (in peius $)^{51}$; c) efecto sustitutivo: aquellas cláusulas que se oponen al convenio empeorando las condiciones del trabajador se tendrán por no puestas ${ }^{52}$. Según Valdés Dal- Ré, este tipo de eficacia es una buena señal del reconocimiento de la importancia social-económica del convenio colectivo y del papel que éste desempeña en la regulación laboral ${ }^{53}$.

Sin embargo, a nosotros nos interesa más otro tipo de eficacia que se denomina normativa ${ }^{54}$, es decir, "que el convenio colectivo no agota su naturaleza qua convenio, sino que completa ésta con el carácter de norma

${ }^{50}$ Correa Carrasco, M., Op. cit., p. 123

${ }^{51}$ Hoy en día se pone en sería duda este efecto debido al artículo 41 del ET.

${ }^{52}$ Correa Carrasco, M., Op. cit., p. 150

${ }^{53}$ VALdÉs DAL-RÉ, F., "Configuración y eficacia de los convenios colectivos extraestatutarios", Madrid, ACARL, 1988, p. 73.

${ }^{54}$ En el fondo la idea de la "eficacia real" está diseñada para los llamados convenios extraestatutarios. No tiene mucho sentido utilizar el término "eficacia real", pues los convenios que se realizan según lo dispuesto en el Título III del ET tienen eficacia normativa, de tal modo que ésta subsume el concepto de eficacia real. Respecto de los convenios extraestatutarios el concepto de "eficacia real" tampoco explica nada, ya que los convenios colectivos pueden ser, en no pocas ocasiones, modificados por pactos de empresa, perdiendo su eficacia real. Además, la jurisprudencia ha puesto de manifiesto, insistentemente, el carácter contractual de los convenios extraestatutarios. Al respecto Cfr. Escribano, J., "Eficacia de los convenios colectivos extraestatutarios en el seno de las nuevas funciones de la autonomía colectiva", en Civitas. Revista española de derecho del trabajo, núm. 97, septiembre-octubre de 1999, passim. 
de lo convenido" 55 . Este carácter de auténtica fuente del derecho de la negociación colectiva se atisba en los siguientes aspectos de su resultado institucional:

1.- La eficacia erga omnes. Si recordamos la tesis expuesta por Aguiló, ésta era una de las características que diferenciaba a las fuentes-acto de las meros actos jurídicos. Pues bien, la eficacia erga omnes puede ser alcanzada de dos formas distintas en el convenio colectivo: a) a priori, cuando existe un marco procedimental por el que se deban desarrollar los convenios y dicho marco posea eficacia general ex lege. b) Ex post, cuando la Administración amplía, por el cumplimiento de determinados requisitos, el marco del convenio ${ }^{56}$. En este segundo caso, la extensión del convenio es un acto administrativo y, por tanto, este acto no forma parte del propio convenio colectivo $^{57}$.

2.- Otra característica importante del convenio colectivo, que pone de manifiesto su fuerza normativa, es que sobre él rige el principio iura novit curia $^{58}$. Este principio es consecuencia directa de la obligación de publicar el convenio colectivo estatutario, de tal forma que los jueces han de conocer el convenio colectivo; la conculcación de este principio es una infracción de Ley alegable en casación o suplicación "con motivo de infracción de normas del ordenamiento jurídico" 59 .

3.- En principio, ni la actuación unilateral del empresario ni la autonomía individual de los trabajadores pueden modificar el convenio colectivo que ya ha sido pactado ${ }^{60}$, y no se puede ignorar la fuerza vinculante de los convenios.

4.- El trabajador de forma individual no es parte legitimada en el proceso de impugnación del convenio colectivo, es decir, sólo los sujetos con capacidad suficiente para ser representantes de los trabajadores y de los empresarios pueden impugnar el convenio ${ }^{61}$. Al igual que sucede con las leyes, que no pueden ser impugnadas por los particulares, el convenio posee también un procedimiento especial para su impugnación.

Nos queda por tratar una de las características más importantes del negocio colectivo como fuente del derecho, que nos permitirá conocer más

\footnotetext{
${ }^{55}$ Alonso Olea, M., Las fuentes del derecho, en especial del Derecho del Trabajo según la Constitución, Madrid, Civitas, 1982, p. 121.

${ }^{56}$ Cfr. Art. 82. 3 ET.

${ }^{57}$ Alonso Olea, M. y Casas Banmonde, M. E., Derecho del Trabajo, cit, p. 836.

${ }^{58}$ Cfr. STCo. 151/1994.

${ }^{59}$ Cfr. Art. 205 LPL.

${ }^{60}$ Cfr. STCo. 107/2000, fundamento jurídico 7.

${ }^{61}$ Cfr. Art. 161 de LPL.
} 
sobre su naturaleza, es decir, si se aproxima más a la ley o al contrato ${ }^{62}$. Nos referimos a la validez del convenio: ¿cuáles son los requisitos de validez del convenio?¿Se asemejan a los de las fuentes-acto?

\section{La validez en el convenio colectivo}

El problema de la validez es uno de los más espinosos de la teoría general del Derecho. No pretendemos, pues, entrar en el fondo del mismo ${ }^{63}$. Sin embargo, este aspecto es importante para nuestra finalidad, ya que, con razón, se ha observado que las fuentes-acto, entre las que nosotros ubicamos a ciertos convenios colectivos, presentan un rasgo distintivo que se exterioriza en el concepto de validez. En este sentido, Aguiló sostiene que las fuentes-acto se caracterizan porque en ellas se produce una disociación en el juicio de validez. Estas dos esferas, que causan la escisión del concepto de validez, pueden ser designadas por medio de los ya clásicos conceptos de vigencia y validez o, si utilizamos otra nomenclatura, existencia y legitimidad del juicio de valide ${ }^{64}$. La primera acepción, que podría ser recogida por la pregunta "que es posible hacer", se refiere a las potestades-competencias que detentan determinados sujetos para realizar una actividad que producirá un resultado institucional; expresado de otro modo: "la posibilidad que tiene una autoridad de crear un resultado institucional" ${ }^{65}$. De esta suerte, el Parlamento tiene la potestad de crear leyes, el Gobierno decretos, y los representantes de los trabajadores y de los empresarios convenios colectivos. Al igual que sucede con la autoridad de los sujetos que pueden producir el convenio colectivo, las otras autoridades (por ejemplo, Parlamento y gobierno) han obtenido su fuerza por medio de una delegación de una autoridad de rango superior ${ }^{66}$. Aguiló sostiene que el criterio de delegación es interno al propio sistema jurídico. Esto implica que, en algún momento, hay que presuponer una autoridad última, es decir, que en consecuencia "habrá algún criterio extrajurídico".

${ }^{62}$ El término ley lo empleamos en un sentido amplio. En puridad, el convenio colectivo se ha comparado, tradicionalmente por la doctrina, con el reglamento.

${ }^{63}$ Una aproximación a estos problemas se puede encontrar, Serrano, J. L., Validez y vigencia, Madrid, Trotta, 1999. En relación con la validez de las reglas que confieren poderes PeñA. A. M., "Reglas de competencia y existencia de las reglas jurídicas" en Doxa 22 (1999), pp. 11 y 12 .

${ }^{64}$ Estas expresiones son las que utiliza Aguiló. Cfr. Aguiló, J., Op. cit., p. 75 y ss.

${ }^{65}$ Agulló, J., ibid. p. 75.

${ }^{66}$ Según Aguiló, si observamos el sistema jurídico, reduciéndolo a las fuentes-acto, desde la perspectiva de lo que se puede hacer, percibiremos la "unidad de autoridades," que constituyen el sistema jurídico. Aguiló, J., Op. cit., p. 76. 
La segunda acepción del concepto validez hace referencia a aquello que "está permitido hacer". Se trata de responder a la pregunta qué contenidos han de ser recogidos por la fuente acto, ¿son estos legítimos o, por el contrario, conculcan alguna norma de rango superior? Pues bien, "esta disociación del juicio de validez, que es el resultado de distinguir entre la delegación de poderes normativos (competencia para producir resultados institucionales) y el establecimiento de deberes relativos al ejercicio de esos poderes normativos (límites en el ejercicio de la competencia) es una característica de las fuentes-acto", que permite diferenciarlas de las fuentes-hecho. Ahora mostraremos cómo esta disociación, que se predica de las fuentes-acto, también es atributo del convenio colectivo. Éste es un signo más de su pertenencia al genus fuentes-acto, que nos permite, por tanto, diferenciarlas de las fuentes-hecho.

Respecto a la existencia del convenio colectivo, es decir, la autoridad que han de ostentar los sujetos para que se produzcan los efectos que, usualmente, producen las fuentes-acto, hay que enfatizar, una vez más, que se establece por Ley, en concreto, en el ET. Tan sólo aquellos sujetos que actúen dentro de unidad supra-empresarial están legitimados para producir dichos efectos, no así el sindicato en el ámbito empresarial ${ }^{67}$. Si los sujetos no tienen la autoridad suficiente, entonces el convenio pierde su fuerza normativa y se convierte en un mero convenio extraestatutario, del cual sólo se puede, según los diferentes autores, predicar eficacia real o carácter de contrato. Al igual que sucede con el resto de las fuentes acto, quiénes sean las autoridades que puedan llevar a cabo el acto que producirá el resultado institucional, se determina en una norma de rango superior.

La legitimidad del convenio colectivo, "aquello que podemos hacer", está delimitada, de modo general, por la adecuación a los distintos elementos que constituyen tanto el estado de cosas, así como a aquellos otros que son necesarios para la realización del acto. Si falta alguno de los requisitos establecidos en el ET el convenio estatutario dejaría de serlo, y se convertiría en convenio extraestatutario.

\section{Conclusiones: ¿cuerpo de contrato, alma de ley; cuerpo de ley, alma de contrato?}

En este trabajo ha prevalecido el interés descriptivo; hemos iniciado nuestras reflexiones realizando un somero recorrido por algunas estructuras

\footnotetext{
${ }^{67}$ En concreto, los sujetos legitimados son los siguientes: por parte de los empresarios, las asociaciones empresariales que representen al menos al diez por ciento. Cfr. Art. 87. 2 a), b), c) y 3 del ET. Por parte de los trabajadores están legitimados el sindicato más representativo a nivel estatal, el sindicato más representativo a nivel de la comunidad autonómica y, por último, el sindicato simplemente más representativo. Cfr. LOLS Arts. 7.1 y 7.2.
} 
-fuentes-acto y RCP, principalmente- que fueron construidas para otras finalidades, y hemos expuesto cómo, por medio de ellas, es posible analizar la negociación colectiva y su resultado institucional: el convenio colectivo. Así pues, hemos de advertir al lector que las deficiencias y virtudes de este trabajo, si las hubiere, sólo pueden ser comprendidas en su justa medida conociendo previamente estos planteamientos, sobre los que nos hemos basado. Esta tarea no será especialmente ardua para el teórico del derecho, pues estos conceptos son herramientas ya básicas para él. No sucederá lo mismo con el iuslaboralista que, ex ante, sólo ha de poseer algunos conocimientos básicos en la rama teórica del derecho.

Sin menospreciar las dificultades expuestas, hemos de defender este esquema explicativo, pues no son pocas las ventajas que contrarrestan estas asperezas conceptuales y metodológicas. El concepto de las fuentes-acto y de las RCP nos permite explicar cualquier fuente-acto con independencia de su naturaleza. Así, se subrayan los paralelismos entre el convenio colectivo y las "clásicas" fuentes-acto, creadas por autoridades políticas. Pero, también, y he aquí el aspecto que se me antoja más destacable, el esquema utilizado no sólo permite estudiar las concomitancias, sino que, además, constituye una buena prueba para detectar las diferencias entre los distintos tipos de fuentes-acto, ya que, por medio de él, se desvelan progresivamente las discrepancias entre los sujetos, los estados de cosas y los actos, y cómo éstas inciden en la formación de resultados institucionales con importantes peculiaridades. En definitiva, esta estructura, permeable al dato positivo, nos ha permitido establecer la tan necesaria relación positiva, presupuesto de todo trabajo iusfilosófico, entre la teoría del derecho y el derecho vigente.

Aunque ya hemos expuesto algunas de las similitudes que guarda el convenio colectivo tanto con las fuentes-acto como con el contrato, ahora es el momento de responder a la pregunta que inquiere por su naturaleza. Una vez más el lector habrá de conformarse con un breve croquis de algunos de sus problemas.

Empecemos por analizar las similitudes que guardan con el contrato privado algunos de los elementos que configuran la negociación colectiva. Ya en el estado de cosas hallamos dos componentes interesantes: la buena fe y el requisito de formalidad que han de respetar los convenios colectivos, pues recordemos que deben ser publicados. La buena fe prohíbe, al igual que sucede en los contratos privados, la intimidación, el ocultamiento de datos objetivos en la negociación, el aprovechamiento del error en que incurra una de las partes. Además, tanto en el contrato privado como en la negociación laboral la buena fe no sólo se predica del momento en que se está produciendo el resultado institucional, sino que también rige en la fase de interpretación. 
La buena fe, que es uno de los elementos fundamentales del acto, encuentra su formulación negativa en la ausencia de violencia. La violencia que en los contratos privados es causa de nulidad, también desempeña un papel fundamental en la negociación colectiva ${ }^{68}$. En ambos casos, se trata de garantizar la libertad de negociación, ya sea de una persona concreta o de los representados por un sindicato.

Por otra parte, al igual que sucede con el convenio colectivo, no pocos contratos privados requieren de algún requisito de carácter formal, sin embargo, como es sabido, nuestro ordenamiento civil recoge el principio de libertad de forma ${ }^{69}$.

Por estas razones, es correcto afirmar que el estado de cosas que es una de las condiciones para producir un contrato privado, guarda importantes analogías con aquel otro que se ubica en la base de la negociación colectiva. De igual modo, se puede sostener que los sujetos, de uno y otro instituto jurídico, poseen algunos paralelismos: ambos han de contar con "capacidad de obrar", esto es, han de ser capaces de obligarse. En último extremo capacidad de obrar quiere decir "capacidad para adquirir o ejercitar derecho y asumir obligaciones", esto es, capacidad para representarse a sí mismo ${ }^{70}$. Esto supone que los sujetos del negocio jurídico poseen "capacidad de obrar", que se traduce, en el seno de la negociación colectiva, en lo que podríamos llamar "representatividad suficiente", es decir, representar a los trabajadores y empresarios en el ámbito en que se produce el convenio, la cual obviamente variará dependiendo de éste. La "capacidad de obrar" que, de modo más general, no es más que la autoridad necesaria para realizar actos jurídicos, se establece del mismo modo en ambos casos: por normas de rango superior que definirán quién ostenta la autoridad, ya sea para negociar o para introducir nuevas normas en el sistema jurídico.

El acto que producirá el resultado institucional convenio colectivo se asemeja también en algunos aspectos al acto que subyace tras el contrato privado. En este último, el acto es la "declaración de voluntad"; en la negociación colectiva será la oferta negociadora, que se produce tras la deliberación de la comisión. De este modo, las reflexiones que se suscitaron sobre la declaración de voluntad han podido ser trasladadas a la negociación colectiva. Los civilistas, al igual que sucede en la negociación colectiva, mantienen que "el supuesto de hecho negocial será generalmente una situación

${ }^{68} C f r$. Art. 89. 1 del ET

${ }^{69}$ Cfr.Art. 1278 Cc.

${ }^{70}$ Diez-Picazo, L., y Gullón, A., Sistema de derecho civil, Madrid, Tecnos, 1989, p. 238. De ahí que cuando ésta no sea suficiente, se tenga que suplir por medio de la figura de un tutor o curador. 
compleja"71. Como ya hemos expuesto, el acto de la negociación jurídica, la negociación en sí, llevada a cabo por la comisión negociadora no es el único presupuesto del antecedente de la negociación colectiva, sino que ha de ser acompañado de los requisitos ya expuestos (los diferentes elementos del estado de cosas y la legitimación de los sujetos).

También, al igual que sucede en el contrato, la negociación colectiva se culmina cuando se alcanza un resultado institucional. Ahora bien, los efectos que produce ese resultado institucional son de diferente índole y, en algunas ocasiones, presentan pocas similitudes con los producidos por el contrato. En este sentido, la negociación colectiva parece distanciarse de la figura del contrato privado y asimilarse a las fuentes-acto; respecto al contrato privado no rige el principio iura novit curia, que se predica normalmente de ciertos convenios colectivos - estatutarios a nivel estatal-y de las fuentes-acto. Además, los contratos no han de ser publicados para que surtan efectos, y sí han de serlo algunas fuentes acto y algunos convenios colectivos. Los negocios jurídicos no obligan usualmente a terceras personas ajenas a la relación negocial; en cambio, tanto las fuentes-acto como los convenios colectivos, casi de ordinario, pueden regular el comportamiento de terceras personas, que no participaron en su proceso de elaboración. El contrato puede ser impugnado individualmente, no así las fuentes-acto, ni los convenios colectivos que poseen "procesos especiales de impugnación"; en el caso de las leyes, el recurso de inconstitucionalidad, cuyos sujetos legitimados están especialmente cualificados, y respecto al negocio colectivo, el procedimiento establecido para la impugnación en la Ley de Procedimiento Laboral, que no puede ser enervado por los trabajadores individuales ${ }^{72}$.

De lo expuesto, podemos deducir que algunos convenios colectivos -los estatuarios- parecen ser un híbrido de contrato y fuente-acto -en concreto del reglamento-, pues poseen elementos de uno y de otra; parafraseando la ya famosa expresión de Carnelutti, tienen cuerpo de contrato y alma de ley.

En principio, nuestras reflexiones ratifican esta teoría. De esta suerte, si examinamos el convenio de forma general, podríamos afirmar que aquellos elementos que conforman el antecedente de la RCP (estado de cosas, sujetos

${ }^{71}$ De Castro, F., Op. cit., p. 25

72 "La impugnación individual ejecutada por un sujeto incluido en el ámbito de la negociación sólo puede proceder por la vía de la petición de "inaplicación" del pacto a una situación concreta". SALDAÑA, E., "Negociación colectiva y lesión de derechos fundamentales: la impugnación indirecta de los convenios colectivos“, en AA.VV. (NAVAro NiETo F., Coord.), Negociación colectiva y solución de conflictos en el sistema español de relaciones laborales: IX Jornadas Universitarias Andaluzas de Derecho del Trabajo y Relaciones Laborales, Trotta, Madrid 1994. 
y acto) son muy similares a los que constituyen el negocio jurídico. En ellos hemos hallado importantes concomitancias: la buena fe, la exclusión de la violencia, la capacidad que necesitan los sujetos para producir resultados institucionales, etc. Pero, de otro lado, si centramos la atención en los efectos que surte el resultado institucional (cierto tipo de convenios colectivos) advertimos que su semejanza sería mayor con las fuentes-acto. El convenio colectivo parecería, pues, una esfinge cuyo basamento tiene forma humana, pero, en cambio, a través de sus fauces se pronuncian normas con la misma eficacia que las creadas por Leviatán.

Sin embargo, estas aseveraciones, que, en buena medida, ratifican nuestro esquema, han de ser matizadas en importantes aspectos, ya que no es sólo el consecuente de las RCP el que presenta importantes similitudes con las fuentes-acto; para que un convenio colectivo surta los mismos efectos que una fuente-acto, su estado de cosas, sus sujetos y su procedimiento han de ser los establecidos por ley y no otros distintos. Será el sindicato más representativo quien deba negociar en un ámbito concreto y, además, deba proceder con buena fe y el resultado se deberá formalizar por escrito y publicarse. Su eficacia "normativa" depende, pues, también de los elementos que conforman el antecedente de la RCP.

Igual sucede con la consecuencia jurídica; sobre su estructura podemos hacer algunas reflexiones que matizan nuestra estructura explicativa (recordemos: el antecedente de la RCP agrupará los elementos similares al negocio jurídico, mientras que en el consecuente hallaremos aquellos que se asimilan a las fuentes-acto). Sirvan los siguientes dos ejemplos, el principio "pacta sunt servanda", que es típico de los contratos, también puede predicarse del resultado institucional convenio colectivo. ¿Cómo es posible explicar que los efectos de los convenios colectivos tengan una vigencia temporal, es decir, una fecha de inicio y otra de conclusión, y que ésta dependa de la voluntad de las partes? A pesar de que algunas normas producidas por autoridades políticas cuenten con una eficacia temporal limitada (Ley de presupuestos generales, por citar un ejemplo prosaico), éste parece ser un efecto atribuible, de ordinario, más a los contratos que a las fuentes-acto.

Ciertamente, la fuerza y la tradición del contrato y de la ley -entendiendo estos dos términos en un sentido amplio- nos hacen pensar si el convenio colectivo es una cosa u otra. La importancia de la teoría del negocio jurídico -sobre todo en los juristas clásicos del XIX, Savigny, Puchta, etc.- puede (entre otros factores, desde luego) ejercer aquí una suerte de vis atractiva, de la que es difícil escapar. Tal vez, por tanto, lo más adecuado sea sostener que las comparaciones -tanto con la ley como con el contrato- no pueden ser interpretadas como un intento nominalista, destinado a atrapar la "esencia" del convenio colectivo. Éste no es ni una cosa ni la otra, es algo distinto, que 
se hace eco de unas necesidades sociales, las cuales difícilmente pueden ser reducidas a las figuras jurídicas con las que usualmente se le compara.

Ahora bien, algunos de los rasgos del convenio colectivo presentan concomitancias con el reglamento y con el contrato, y ello nos permite desde luego desentrañar, de forma más sencilla, los contornos de la institución que nos ocupa. Ello -insisto, de nuevo- no significa que su "esencia" sea la de un contrato o la de un reglamento. Posiblemente, subsumir el convenio colectivo en unos esquemas pergeñados ex ante y a priori-en este último sentido, sin tener en cuenta la experiencia jurídica- no nos conducirá -me parece- a buen puerto.

Habremos de contentarnos, pues, con una conclusión más modesta, a saber: el convenio colectivo es una institución con peculiaridades propias, cuyo proceso de elaboración puede ser explicado, relativamente bien, por medio del concepto de las RCP. Algunas veces - cuando siga determinados requisitos establecidos legalmente- poseerá eficacia general y se asemejará -en algunos aspectos- a las denominadas fuentes-acto. Otras, cuando haya sido creado por un procedimiento distinto, se parecerá más a un contrato.

De todo lo expuesto podemos obtener algunas conclusiones provisionales y generales:

1. Existe una necesidad de aproximación de la teoría general del derecho a los problemas surgidos en el campo del derecho positivo y, además, parece que aquélla puede ser una herramienta útil para solventarlos.

2. Tanto el concepto de las RCP como la estructura de las fuentes-acto parecen esquemas lo suficientemente maleables como para explicar, desde la teoría general del derecho, determinadas instituciones jurídicas. En este sentido, son un buen ejemplo, una concreción de la necesidad reflejada en el punto 1 .

3. El convenio colectivo, al menos el estatutario, parece poder subsumirse bajo la estructura propuesta por Aguiló con el nombre fuentes-acto.

4. La primera parte de las RCP, que articulan la estructura del convenio, guarda importantes similitudes con los contratos; en cambio, el consecuente de la RCP se asemeja a los efectos producidos por las fuentes-acto. Ahora bien, sobre esta regla se pueden hacer algunas salvedades, que, sin embargo, no invalidan el esquema general, ya que éste parece exponer importantes rasgos esenciales del convenio colectivo.

5. La definición de los distintos elementos que conforman el convenio colectivo es una tarea jurídico-positiva, es decir, será el legislador ordinario quien, perfilándolos, asemeje o distancie la figura del convenio colectivo al contrato o a las fuentes-acto.

6. A pesar de que del convenio colectivo se pueden predicar ciertos rasgos que lo asemejan a los contratos y a determinadas fuentes-acto, y ello 
nos permite conocerlo de un modo más adecuado, éste no es, en puridad, ni un contrato ni una fuente-acto. Se trata de una figura que tiene sus propios rasgos específicos. 